\title{
Enhancement by cholera toxin of IgA secretion from intestinal crypt epithelium*
}

\author{
S R HAMILTON, $†$ D F KEREN, $\ddagger$ J K BOITNOTT, S M ROBERTSON, $\S$ \\ AND J H YARDLEY \\ From the Department of Pathology, The Johns Hopkins University School of Medicine and Hospital; \\ and Mergenthaler Laboratory for Biology, The Johns Hopkins University, Baltimore, Maryland, USA
}

SUMMARY Studies of the effects of cholera toxin on the intestine have produced conflicting results regarding stimulation of $\mathrm{IgA}$ secretion. In the present study rabbit ileal loops were perfused with saline, and the IgA content of the perfusate was assessed by immunoradiometric assay. Crypt epithelial IgA content in biopsies was studied by immunofluorescence. Cumulative loop fluid IgA production 300 minutes after exposure to cholera toxin was $6216 \pm 993 \mu \mathrm{g} / \mathrm{cm}$ compared with $4646 \pm 953 \mathrm{\mu g} / \mathrm{cm}$ in controls $(\mathrm{P}<0 \cdot 20)$. However, rate of fluid IgA production above baseline at 300 minutes was $1742 \pm 181 \mu \mathrm{g} / \mathrm{h} / \mathrm{cm}$ in cholera loops and $1049 \pm 310 \mu \mathrm{g} / \mathrm{h} / \mathrm{cm}$ in controls, and the mean difference between the cholera and control loops was statistically significant $(\mathbf{P}<0.05)$. In biopsies, mean rank of crypt epithelial IgA at 300 minutes was decreased compared with controls $(\mathrm{P}<0.05)$. The findings of increased rate of fluid IgA production and decreased epithelial IgA suggest that a single dose of cholera toxin enhanced secretion of IgA from crypt epithelium into the intestinal lumen, although the magnitude of the enhancement was not great.

IgA is the predominant immunoglobulin in plasma cells of the mucosa ${ }^{12}$ and in secretions ${ }^{34}$ of the gastrointestinal tract. Further, IgA antibodies against intraluminal organisms $\mathrm{s}^{5-10}$ and their products $^{1112}$ have been demonstrated in intestinal secretions. These antibodies appear to be important in local protection against infection, functioning by mechanisms which include (1) reducing intraluminal and mucosal colonisation by microorganisms through agglutination and reduction in mucosal adherence, and (2) interfering with the action of microbial products such as toxins. ${ }^{73-17}$ It is now well-established that IgA is synthesised by plasma cells in the lamina propria, accumulated within crypt epithelial cells after addition of secretory component, and finally secreted into the intestinal lumen. ${ }^{131518-22}$ Little is known, however, about

*This paper was presented in part at the meetings of the Federation of American Societies for Experimental Biology, Atlantic City, NJ, 1975 and Chicago, IL, 1977.

$\dagger$ Address for reprint request: Stanley R Hamilton, MD, Department of Pathology. The Johns Hopkins Hospital. 600 North Wolfe Street, Baltimore, Maryland 21205 , USA.

¿Present address: Dr D F Keren, Department of Pathology, University of Michigan Medical School, Ann Arbor, Michigan 48105, USA. §Present address: Dr S M Robertson, Microbiology Department, Southwestern Medical School, University of Texas Health Science Center, 5323 Harry Hines Blvd., Dallas, Texas 75235, USA.

Received for publication 13 November 1979 factors which influence intestinal IgA secretion, including factors related to infectious diseases.

Cholera, the diarrhoeal disease produced by Vibrio cholerae, is mediated by enterotoxin. In experimental studies, exposure of the mucosa of rabbit intestinal loops to cholera toxin (CT) causes secretion of large amounts of mucin-rich fluid. ${ }^{23}$ This enhanced secretion has a histological counterpart in depletion of mucin from epithelial goblet cells. ${ }^{24}$ In addition to mucin, secretory IgA has been reported to be present in cholera fluid from rabbit ileal loops ${ }^{25}$ and man. ${ }^{34}$ Also, in a previous study ${ }^{26}{ }^{27}$ we found that crypt epithelial IgA content as assessed by immunofluorescence showed a progressively greater decrease in loops exposed to CT than in control loops. These findings, therefore, raised the possibility that $\mathrm{CT}$ induced IgA secretion from crypt epithelium into the intestinal lumen. However, in our previous study ${ }^{27}$ and one by other investigators, ${ }^{28}$ the $\operatorname{IgA}$ content of the fluid produced by cholera loops was no greater than control loops. Because of these paradoxical results, an experimental model using saline perfusion of the loops to provide optimum specimen collection was used for detailed study of the effects of CT upon IgA secretion. 


\section{Methods}

EXPERIMENTAL TECHNIQUES

Four fasted adult female New Zealand white rabbits weighing 2 to $3 \mathrm{~kg}$ were anaesthetised with intravenous sodium pentobarbital. In each animal two loops of distal ileum 15 to $20 \mathrm{~cm}$ in length were isolated with their blood supply intact. Silastic tubing (Dow-Corning Corporation Medical Products, Midland, Michigan) was secured into the ends of each loop. Loops were flushed with $0.01 \mathrm{M}$ phosphate buffered saline at $\mathrm{pH} 7 \cdot 2$ (PBS) until the effluent was clear. Intra-abdominal temperature was maintained at $37^{\circ} \mathrm{C}$ throughout the experiment with an external heat lamp. Five percent dextrose in normal saline was given intravenously to assure adequate hydration.

After preparation of loops, a biopsy for immunohistological study was obtained from each loop by removal of a short segment from the proximal end. Two millilitres of PBS were instilled into each loop at time designated -60 minutes, and the ends of the Silastic tubing were clamped. After 15 minutes, the fluid in each loop was collected by gentle flushing with air and $2 \mathrm{ml}$ of PBS were again instilled into the loop. The collected fluid was weighed and frozen immediately at $-20^{\circ} \mathrm{C}$. PBS instillation and collection were repeated three additional times to provide a 60-minute baseline period. At zero time, $100 \mu \mathrm{g}$ purified CT (Schwarz-Mann Division of Becton, Dickinson Inc., Orangeburg, New York) in $2 \mathrm{ml}$ PBS were placed in one loop, designated the cholera loop, and $2 \mathrm{ml}$ PBS alone were placed in the second loop, designated the PBS loop. After 15 minutes, cycles of instillation and flushing of $2 \mathrm{ml}$ PBS every 15 minutes were resumed in both loops until 120 minutes. For the remainder of the experiment the $2 \mathrm{ml}$ volumes of PBS were left in each loop for 30 minutes. The experiment was terminated at 300 minutes. The loops were measured and again biopsied.

Rate of net fluid production from each loop in each collection period was calculated in $\mu$ l of fluid, in excess of the $2 \mathrm{ml}$ initially instilled, per hour per $\mathrm{cm}$ of loop ( $1 \mathrm{~g}$ of fluid was assumed to equal $1 \mathrm{ml}$ ). Cumulative net fluid production $(\mu \mathrm{l} / \mathrm{cm})$ at the end of each collection period was determined, as were the differences in production rate and in cumulative net fluid production between the two loops in each animal for each time period.

\section{ASSAY FOR FLUID IGA CONTENT}

The two-site immunoradiometric assay used monospecific goat anti-rabbit alpha chain absorbed to bromacetyl cellulose (BAC) and ${ }^{125}$ I-labelled goat anti-rabbit Fab. The assay was performed as de- scribed previously ${ }^{29}$ Each specimen was thawed and then assayed in duplicate at two dilutions. Concentration of IgA in $\mathrm{mg} / \mathrm{ml}$ in each specimen fluid was determined from a standard curve of purified trypsin-resistant sIgA derived from rabbit colostrum. Fluid IgA production $(\mu \mathrm{g} / \mathrm{h} / \mathrm{cm})$ for all time intervals was calculated from the specimen $\operatorname{IgA}$ concentration, specimen volume, and the loop length during the time interval. Cumulative $\operatorname{IgA}$ production $(\mu \mathrm{g} / \mathrm{cm})$ for each loop in each animal throughout the experiment was also determined. The difference in IgA concentration, in rate of production, and in cumulative production between the two loops in each animal were calculated for each time period.

IMMUNOHISTOLOGICAL TECHNIQUES

All biopsy specimens were mounted in Tissue-Tech II OCT Compound (Lab-Tek Products, Division of Miles Laboratories, Inc., Naperville, Illinois), snap frozen in liquid nitrogen, and stored at $-20^{\circ} \mathrm{C}$. Frozen sections $6 \mu \mathrm{m}$ thick were prepared. IgA content of crypt epithelial cells was studied in a set of frozen sections stained with fluorescein isothiocyanate conjugated (FITC) monospecific goat antirabbit alpha chain (provided by Dr John $\mathbf{J}$ Cebra, The Johns Hopkins University, Baltimore, Maryland). The reagent was prepared as described previously. ${ }^{30}$ In preliminary studies, serial dilutions of the reagent were tested for optimum sensitivity to the differences in crypt IgA content which were observed. The maximum dilution that showed consistent staining of the lamina propria plasma cells $(1: 40)$ was selected as the working dilution. Each set of stained slides was coded. The coded slides were ranked for IgA content of the crypt epithelial cells using a Carl Zeiss Standard RA dark field microscope with halogen quartz light source, FITC primary filter (range $460-490 \mathrm{~nm}$ ), and Zeiss 50 secondary filter (Carl Zeiss, Inc., New Yori). With the ranking system the slides were arranged in order from least to most $\operatorname{IgA}$ content and then assigned the corresponding position number which was used for statistical analysis.

\section{STATISTICAL ANALYSIS}

For net fluid production and fluid $\operatorname{IgA}$ data, the mean and standard error of the mean (SEM) for comparable loops were calculated for each collection period. Mean differences between the loops and SEMs were also determined. Log mean rank and SEM were calculated for crypt IgA content at -60 and 300 minutes. Tests for statistical significance included two-tailed $t$ test for significant difference between means based upon paired data and evaluation of $95 \%$ confidence limits as expressed by two SEMs for mean difference from zero. The signifi- 
cance of changes in crypt IgA with time were determined by linear regression analysis. ${ }^{31}$

\section{Results}

\section{FLUID PRODUCTION}

Net absorption was demonstrated initially in both the cholera and PBS loops, as indicated by the negative slopes of the cumulative net fluid production curves (Fig. 1). From 90 minutes onward net fluid secretion occurred in the cholera loops, while the PBS loops continued to show net absorption or only slight net fluid secretion. Cumulative net fluid production by cholera loops was greater than PBS loops at 105, 150, and 210 minutes onward $(\mathrm{P}<0.05)$.

\section{FLUID IGA CONTENT}

Both cholera and PBS loops showed a consistent trend of rising fluid IgA concentrations with time, and there were no statistically significant differences between the loops (Table). Fluid IgA production (Fig. 2) was similar for each type of loop for the 60-minute control period preceding instillation of CT into the cholera loops. By the end of the experimental period at 300 minutes, all cholera loops had produced more IgA than the corresponding PBS

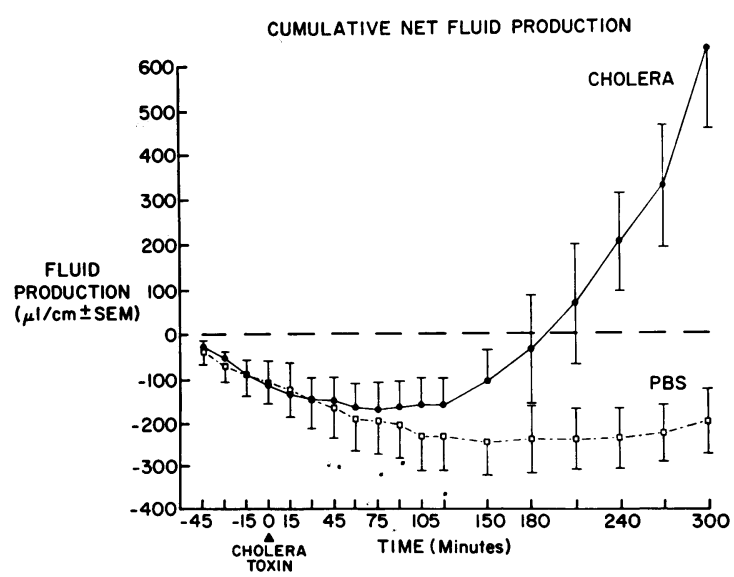

Fig. 1 Mean cumulative net fluid production in cholera and PBS loops.

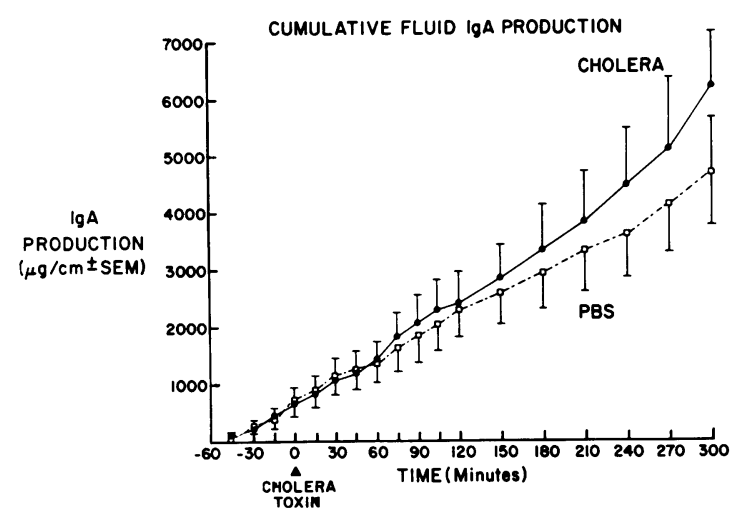

Fig. 2 Mean cumulative fluid $\operatorname{Ig} A$ production in cholera and PBS loops.

loops, although the greater cumulative fluid $\operatorname{IgA}$ production (Table) was not significantly different from the PBS loops $(P<0 \cdot 20)$. However, during the third and fifth hours of the experiment, the rates of IgA production in the cholera loops were greater $(\mathrm{P}<0.05)$ than during the -60 to 0 minute baseline period (Fig. 3). In contrast, at no time were the rates in the PBS loops significantly different from baseline. Furthermore, the mean difference in rate of $\operatorname{IgA}$ production between the cholera and PBS loops was significant at 300 minutes $(\mathrm{P}<0.05)$. Thus, the cholera loops produced IgA more rapidly during the

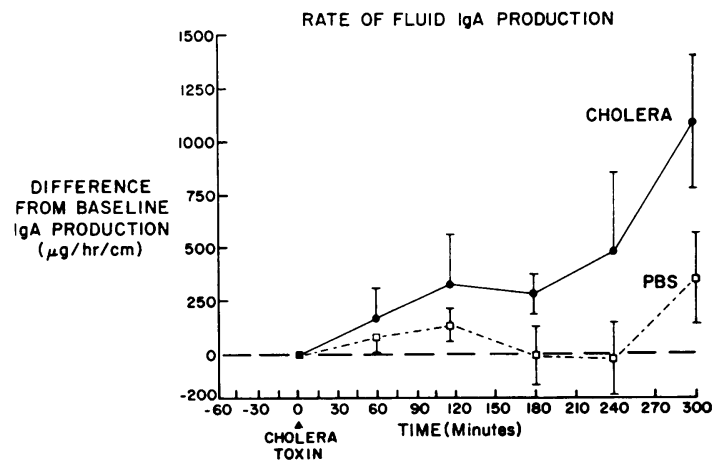

Fig. 3 Mean difference from baseline rate of fluid IgA production in cholera and PBS loops.

Table Summary of fluid IgA results

\begin{tabular}{|c|c|c|c|}
\hline Type of loops & $\begin{array}{l}\text { Mean IgA concentration } \\
240-300 \text { minutes* }(\mathrm{mg} / \mathrm{ml})\end{array}$ & $\begin{array}{l}\text { Mean rate of } \mathrm{IgA} \text { production } \\
240-300 \text { minutes* }(\mu \mathrm{g} / \mathrm{h} / \mathrm{cm})\end{array}$ & $\begin{array}{l}\text { Mean cumulative } \lg A \text { production } \\
300 \text { minutes* }(\mu \mathrm{g} / \mathrm{cm})\end{array}$ \\
\hline Cholera loops & $2 \cdot 5 \pm 0.7$ & $1742 \pm 181$ & $P<0.20$ \\
\hline PBS loops & $2.7 \pm 0.6$ & $1049 \pm 310$ & $4646 \pm 953$ \\
\hline
\end{tabular}

* Mean \pm standard error of the mean.

+ Based upon mean difference from baseline rate of IgA secretion. 
latter part of the experiment when fluid production was increased.

\section{CRYPT EPITHELIAL IGA CONTENT}

The cholera loops consistently showed less crypt IgA at 300 minutes than the PBS loops at 300 minutes or the cholera and PBS loops at -60 minutes. In addition, mean rank of crypt epithelial IgA in the 300-minute cholera loop specimens was statistically significantly less than the other three specimens $(\mathrm{P}<0.05)$.

\section{Discussion}

The technique of loop perfusion used in this study was specifically designed to evaluate the effects of CT upon fluid IgA production. Use of loop perfusion for such studies has three major advantages over unperfused loops: (1) the mucosa in cholera and control loops was bathed with PBS solution which varied little in composition, in contrast with the striking differences in fluid composition when unperfused loops were used; matrix effects on the immunoradiometric assay for IgA were therefore less likely; (2) the presence of fluid in the lumen of the loops was more analogous to the normal intestine; (3) the collection of secretions, particularly the tenacious cholera fluid, was more complete. Thus, we believe that this perfusion study showing increased rate of fluid IgA production by cholera loops provided more reliable measurements of fluid IgA output than previous studies using unperfused loops. ${ }^{2 \pi} 28$

Crypt epithelial IgA as assessed by immunofluorescence in our studies represents accumulated secretory IgA. The content is thus affected by uptake of $\operatorname{IgA}$ from plasma cells in the lamina propria as well as by secretion of IgA into the intestinal lumen. Further, the quantity of $\operatorname{IgA}$ represented by the decrease in epithelial IgA immunofluorescence in our study is, of course, unknown. Nevertheless, the finding in cholera loops of decreased crypt IgA content as well as increased rate of fluid IgA production suggests that $\mathrm{CT}$ enhanced transfer of secretory $\operatorname{IgA}$ from the epithelium into the fluid. On the other hand, it is also evident that a single dose of CT did not enhance IgA secretion to a degree that was in any way comparable with its striking effects upon fluid production and goblet cell mucin content.

From the standpoint of immunity to intestinal infection, enhanced release of IgA antibodies against the offending organisms and their products has the theoretical benefit of augmenting host defence against the infection. In the case of cholera, CTenhanced secretion of $\operatorname{IgA}$ anti-vibrio and anti-toxin antibodies could further impair colonisation and augment clearance of organisms as well as neutralisation of released CT. Further, enhancement of secretion early in the course of infection could be particularly beneficial. However, in our experimental study of the effects of one dose of CT, an increase over baseline IgA secretion was not demonstrated until the third hour-that is, after CTinduced fluid secretion was well established. Thus, there was clearly no early enhancement of aritibody secretion. Also, the amount of additional IgA released during the five hours after the single dose of CT was not statistically significant as compared with control loops. Therefore, although the experimental model is very different from infection with toxigenic vibrios, our findings do not support the hypothesis that CT-induced enhancement of antibody secretion is of sufficient magnitude to benefit the immune host by inhibiting the infection or effects of cholera toxin.

This work was supported by US Army Medical Research and Development Command contract DAMD 17-75-C-5002. We appreciate the advice of Dr N F Pierce. We thank Mrs Gertrude Brown, Mrs Cariel Edwards, Mr G Horne, Mrs Nancy Folker, and Mrs Cheryl Hamilton for their assistance.

\section{References}

${ }^{1}$ Crabbe PA, Carbonara AO, Heremans JF. The normal human intestinal mucosa as a major source of plasma cells containing $\gamma \mathrm{A}$-immunoglobulin. Lab Invest 1965; 14: 235-48.

${ }^{2}$ Rubin W, Fauci AS, Sleisenger MH, Jeffries GH. Immunofluorescent studies in adult celiac disease. $J$ Clin Invest 1965 ; 44: 475-85.

${ }^{3}$ Northrup RS, Bienenstock J, Tomasi TB Jr. Immunoglobulins and antibody activity in the intestine and serum in cholera. I. Analysis of immunoglobulins in cholera stool. J Infect Dis 1970; 121 suppl: 137-41.

${ }^{4}$ Waldman RH, Benčič Z, Sakazaki R, et al. Cholera immunology. I. Immunoglobulin levels in serum, fluid from the small intestine, and feces from patients with cholera and noncholeraic diarrhea during illness and convalescence. J Infect Dis 1971; 123: 579-86.

${ }^{5}$ Ogra PL, Karzon DT, Righthand F, MacGillivray M. Immunoglobulin response in serum and secretions after immunization with live and inactivated polio vaccine and natural infection. $N$ Engl J Med 1968; 279: 893-900. ${ }^{6}$ Girard JP, de Kalbermatten A. Antibody activity in human duodenal fluid. Eur J Clin Invest 1970; 1 : 188-95. 'Hanson LA, Brandtzaeg P. Secretory antibody systems. In: Stiehm ER, Fulginiti VA, eds. Immunologic disorders in infants and children. Philadelphia: W B Saunders, 1973: 107-26.

${ }^{8}$ Waldman RH, Benčič Z, Sinha R, et al. Cholera immunology. II. Serum and intestinal secretion antibody 
response after naturally occurring cholera. $J$ Infect Dis 1972; 126: 401-7.

${ }^{9}$ Porter P, Kenworthy R, Noakes DE, Allen WD. Intestinal antibody secretion in the young pig in response to oral immunization with Escherichia coli. Immunology 1974; 27: 841-53.

${ }^{10}$ Keren DF, Holt PS, Collins HH, Gemski P, Formal SB. The role of Peyer's patches in the local immune response of rabbit ileum to live bacteria. J Immunol 1978; 120: $1892-6$.

"Yardley JH, Keren DF, Hamilton SR, Brown GD. Local (immunoglobulin A) immune response by the intestine to cholera toxin and its partial suppression with combined systemic and intra-intestinal immunization. Infect Immun 1978; 19: 589-97.

${ }^{12}$ Hamilton SR, Yardley JH, Brown GD. Suppression of local intestinal immunoglobulin $\mathrm{A}$ immune response to cholera toxin by subcutaneous administration of cholera toxoids. Infect Immun 1979; 24: 422-6.

${ }^{13}$ Tomasi TB, Grey HM. Structure and function of immunoglobulin A. Prog Allergy 1972; 16: 81-213.

${ }^{14}$ Freter R. Gut-associated immunity to cholera. In: Barau D, Burrows W, eds. Cholera. Philadelphia: W B Saunders, 1974: 315-31.

${ }^{15}$ Heremans JF. Immunoglobulin A. In: Sela M, ed. The antigens, vol. 2. New York: Academic Press, 1974: 365-522.

${ }^{16}$ Waldman RH, Ganguly R. Immunity to infections on secretory surfaces. J Infect Dis 1974; 130: 419-40.

${ }^{17}$ Brandtzaeg P, Baklien K. Immunohistochemical studies of the formation and epithelial transport of immunoglobulins in normal and diseased human intestinal mucosa. Scand J Gastroenterol 1976; 11 (suppl 36): $1-45$.

${ }^{18}$ Tomasi TB, Tan EM, Solomon A, Prendergast RA. Characteristics of an immune system common to certain external secretions. J Exp Med 1965; 121: 101-24.

${ }^{19}$ South MA, Cooper MD, Wollheim FA, Hong R, Good RA. The IgA system. I. Studies of the transport and immunochemistry of IgA in the saliva. J Exp Med 1966; 123: 615-27.

${ }^{20} \mathrm{O}$ 'Daly JA, Craig SW, Cebra JJ. Localization of $b$ markers, $\alpha$-chain and SC of SIgA in epithelial cells lining Lieberkühn crypts. J Immunol 1971; 106: 286-8.

${ }^{21}$ Brandtzaeg P. Mucosal and glandular distribution of immunoglobulin components. Immunohistochemistry with a cold ethanol-fixation technique. Immunology 1974; 26: 1101-14.

${ }^{22}$ Poger ME, Lamm ME. Localization of free and bound secretory component in human intestinal epithelial cells. A model for the assembly of secretory IgA. J Exp Med 1974; 139: 629-42.

${ }^{23}$ Yardley JH, Brown GD. Horseradish peroxidase tracer studies in the intestine in experimental cholera. $L a b$ Invest 1973; 28: 482-93.

${ }^{21}$ Yardley JH, Bayless TM, Luebbers EH, Halsted $\mathrm{CH}$, Hendrix TR. Goblet cell mucus in the small intestine. Findings after net fluid production due to cholera toxin and hypertonic solutions. Johns Hopkins Med J 1972; 131: $1-10$.

${ }^{25}$ Wood S, Clem LW. The use of cholera toxin for obtaining rabbit secretory immunoglobulins. $J$ Immunol Methods 1974; 4: 207-12.

${ }^{26}$ Hamilton SR, Keren DF, Boitnott JK, Yardley JH. Reduction of $\operatorname{IgA}$ and mucin in intestinal epithelium after exposure to cholera toxin (abstract). Fed Proc $1975 ; 34: 386$.

${ }^{27}$ Hamilton SR, Keren DF, Boitnott JK, Yardley JH. IgA content of intestinal epithelium and secreted fluid in experimental cholera (abstract). Fed Proc 1977; 36: 1054.

${ }^{28}$ Borthistle BK, Isobe K, Brown WR. Studies on translocation of immunoglobulins across intestinal epithelium. III. Failure of cholera enterotoxin to stimulate secretion of IgA by rabbit intestine. Am J Dig Dis 1978; 23: 134-6.

${ }^{29}$ Robertson SM, Cebra JJ. A model for local immunity. Ric Clin Lab 1976; 6 suppl: 105-19.

${ }^{30}$ Cebra JJ, Goldstein G. Chromatographic purification of tetramethylrhodamine-immune globulin conjugates and their use in the cellular localization of rabbit $\gamma$-globulin polypeptide chains. J Immunol 1965; 95: 230-45.

${ }^{31}$ Dixon WJ, Massey FJ Jr. Introduction to statistical analysis. New York: McGraw-Hill, 1969: 200-15. 